\title{
Pan-human coronavirus and human bocavirus SYBR Green and TaqMan PCR assays; use in studying influenza $A$ viruses co-infection and risk of hospitalization
}

\author{
E. A. Goka · P. J. Vallely · K. J. Mutton · P. E. Klapper
}

Received: 10 August 2014 / Accepted: 24 November 2014 / Published online: 5 December 2014

(C) Springer-Verlag Berlin Heidelberg 2014

\begin{abstract}
Purpose Influenza A viruses, human coronaviruses $(\mathrm{hCoV})$ and human bocavirus $(\mathrm{hBoV})$ are emerging respiratory viruses. This study investigated the association between influenza A viruses co-infection with $\mathrm{hBoV}$ and $\mathrm{hCoV}$ and severity and the sensitivity of a real-time polymerase chain reaction (RT-PCR) assay for identification of 15 coronaviruses.

Methodology Published sequences for the 15 human coronaviruses were used to design a consensus PCR targeting the replicase open reading frame $1 \mathrm{~b}$. A previously published PCR targeting the NS1 Gene of all known human bocavirus strains was also utilized. A series of 217 samples from patients aged $37.7(\mathrm{SD} \pm 30.4)]$ with seasonal influenza A viruses (SeasFluA) identified between 06/2011 and 06/2012 in NW England were tested for $\mathrm{hCoV}$ and $\mathrm{hBoV}$ using RT-PCR. Association between coinfection and disease outcome was assessed using logistic regression.

Results The limit of detection of hCoV RT-PCR assay was 2 copies/ $\mu$ of human coronavirus RNA template, a sensitivity comparable to a previously published SYBR green assay for human coronaviruses. A total of $12 \mathrm{hCoV}$ and $17 \mathrm{hBoV}$ were identified in the 217 influenza A positive samples. A higher proportion $(61.5 \% ; 8 / 13)$ of SeasFluA $/ \mathrm{hBoV}$ co-infections were identified in patients
\end{abstract}

E. A. Goka $(\bowtie) \cdot$ P. J. Vallely · K. J. Mutton · P. E. Klapper Faculty of Medical and Human Sciences, Institute of Inflammation and Repair, University of Manchester, 1st Floor Stopford Building, Oxford Road, Manchester M13 9PL, UK e-mail: edwardgo.ka@postgrad.manchester.ac.uk

K. J. Mutton · P. E. Klapper

Department of Clinical Virology, Central Manchester Universities NHS Foundation Trust, Oxford Road, Manchester M13 9WL, UK that were admitted either to a general ward or the intensive care unit compared to $44.3 \%$ (66/149) of single SeasFlu A virus infections (OR $2.595 \%$ CI $0.67-9.34, p=0.17$ ). In a stratified analysis, there was a trend towards higher association between FluA, hCoV and $\mathrm{hBoV}$ with increasing age (especially in patients aged 24-45 years and $>65$ year old). Conclusion Our hCoV RT-PCR protocol appeared to be of adequate analytical sensitivity for diagnosis. More and larger studies are needed to confirm the role of hCoV, $\mathrm{hBoV}$ in causing severe disease when they co-infect with influenza A viruses.

Keywords Influenza A virus - Coronavirus - Bocavirus · SYBR Green /TaqMan RT-PCR assay · Co-infection · Hospitalization

\section{Introduction}

Influenza A viruses are a significant cause of acute lower respiratory tract infections (ALRI), with $13.0 \%$ of all children with influenza infection developing ALRI-equivalent to 20 million (95\% CI 13-32 million) ALRI cases per year [1]; and according to these authors, in 2008, between 28,000 and 111,500 children younger than 5 years died of influenza-associated ALRI. Among potential co-pathogens, human coronaviruses (hCoV) and human bocavirus $(\mathrm{hBoV})$ are important emerging respiratory viruses $[2,3]$.

Coronaviruses infect a wide variety of hosts (animals and humans); Alphacoronaviruses and Betacoronaviruses infect mammals, whereas Gammacoronaviruses infect birds [4]. Most of the human coronaviruses (Alphacoronaviruses 229E and NL63 and Betacoronaviruses OC43, HKU1) cause mild influenza like illnesses, however in 2003, the severe acute respiratory syndrome (SARS) 
coronavirus caused a very severe form of respiratory disease in humans globally [5], resulting in over 900 deaths [6]. On 21 September 2012, a novel coronavirus was identified in lower respiratory tract of an adult male Qatari national in London [7]. Three months earlier (13 June 2012), Dutch researchers identified a similar virus in a Saudi Arabian national presenting with pneumonia [8-10]. As of 11 June, 2014, 699 laboratory-confirmed cases of human infection with MERS-CoV have been reported to WHO, including at least 209 deaths [6].

Human bocavirus, was first discovered in respiratory specimens of patients with lower respiratory disease in 2005 by Allander et al. [11] using a random polymerase chain reaction (PCR)-cloning-sequencing protocol. Reviews by Schildgen et al. [3] and Zhenqiang et al. [12] showed that, since 2005, over 40 studies conducted globally identified human bocavirus in children with acute respiratory virus infections; and that most of these prevalence studies found $\mathrm{hBoV}$ occurring mainly together with other viruses. The significance of human bocaviruses in causing serious clinical disease is still under debate, with some studies finding that bocavirus may cause significant ALRI $[3,12]$, and others finding they only cause mild illness [3, $13,14]$.

$\mathrm{HBoV}$ infection is reported to mainly occur as a coinfection with other respiratory viruses; some zoonotic $\mathrm{hCoV}$ have been associated with sever lower repiratory tract infection (LRTI). However these viruses are not, at present, routinely tested in clinical settings due to a lack of knowledge on the significance of these viruses in causing severe disease. Some recent studies have indicated that respiratory virus co-infections increases disease severity $[15,16]$, however the pattern of co-infection between influenza $\mathrm{A}$ viruses and $\mathrm{hCoV}$ and $\mathrm{hBoV}$ and their association with severe disease has not been clearly elucidated. We designed primers and optimized a realtime polymerase chain reaction (RT-PCR) assay for identification of 15 coronaviruses and used the RT-PCR targeting the NS1 region of the $\mathrm{hBoV}$ described by Qu et al. [17] to investigate the patterns of co-infections between influenza $\mathrm{A}$ virus with $\mathrm{hCoV}$ and $\mathrm{hBoV}$ and their association with severe clinical disease.

\section{Methodology \\ Clinical samples and setting}

We tested for hCoV and $\mathrm{hBoV}$ in 217 samples randomly selected from 596 influenza A viruses identified from 3,804 samples received between 24th June 2011 and 30th June 2012 at the Manchester Microbiology Partnership Laboratory (MMPL), a reference laboratory for the North West
England serving a population of around 7 million people [18]. Influenza A viruses were identified using a well characterised in-house duplex real-time polymerase chain reaction assays and influenza A (H1N1) subtyped using the Public Health England (PHA) (H1)v) assay [19]. The PCRs were run on the ABI7500 real-time PCR instrument (Applied Biosystems, Warrington, United Kingdom). Samples were from patients aged between 1 and 98 years old (mean age 37.7, $\mathrm{SD} \pm 30.4$ ), seen as outpatients (at medical centres, clinics or hospitals), or admitted to a hospital in North West England.

Primers, templates and probes for $\mathrm{hCoV}, \mathrm{hBoV}$

To design primers for $\mathrm{hCoV}$, complete genomic sequences for 15 coronavirus (Table 1), were downloaded from the GenBank (and details of their GenBank accession numbers available on request), aligned with BioEdit Sequence alignment Editor version 7.1.3.0 [20] and a consensus blasted using the BLAST program [GenBank, Bethesda MD, 20894 USA]; limiting the search to nucleotide collection (nt) database and organism Coronaviridae. One pair of primers targeting the region of the replicase open reading frame $1 \mathrm{~b}(\mathrm{ORF} 1 \mathrm{~b})$ non-structural protein 15 (nsp15; XendoU/NendoU) uridylate specific endonuclease, which is highly conserved among all coronaviruses [21, 22] was selected; forward primer: $5^{\prime}$-TGGGGA GTAATGAACCCGGTA- ${ }^{\prime}$ and reverse primer: 5'-ACATGT $^{\prime}$ AAAAGAGCTAATAACAC-3' (Eurofins MWG Operon,

Table 1 Coronaviruses used in the design of pan-coronavirus primers (downloaded from GeneBank on 18th December, 2011)

\begin{tabular}{llr}
\hline & Coronavirus & $\begin{array}{c}\text { Number identified } \\
\text { and downloaded }\end{array}$ \\
\hline 1 & Human coronavirus HKU1 & 20 \\
2 & Human coronavirus NL63 & 2 \\
3 & Human coronavirus OC43 & 4 \\
4 & Human coronavirus 229E & 1 \\
5 & Bovine coronavirus & 12 \\
6 & Porcine haemagglutinating virus & 2 \\
7 & Murine hepatitis virus & 21 \\
8 & Equine coronavirus & 3 \\
9 & Rat coronavirus & 1 \\
10 & Bat coronavirus & 31 \\
11 & Avian infectious bronchitis virus & 41 \\
12 & Canine coronavirus & 1 \\
13 & Sambar deer coronavirus & 1 \\
14 & Bat SARS coronavirus & 10 \\
15 & Duck coronavirus & 1 \\
& Total & 151 \\
\hline
\end{tabular}


Germany); probe 5'-FAM-TTGTGTAAAGATAGTGGAG GTT-MGB -3' (Applied Biosystems, Warrington, UK).

The primer and template described by Qu et al. [17], GenBank accession no. NC_007455; forward primer 5'-TAATGACTGCAGACAACGCCTAG-3', reverse primer 5'-TGTCCCGCCCAAGATACACT-3' (Eurofins MWG Operon, Ebersberg Germany); probe 5' FAM-TTCCACCCAATCCTGGT-MGB-3' (Applied Biosystems, Warrington, $\mathrm{UK}$ ), were used for identification of $\mathrm{hBoV}$.

Determination of analytical sensitivity and reproducibility of RT-PCR protocols

To determine analytical sensitivity, synthetic DNA templates were constructed using sequence nt position 20062-20134 of Bovine coronavirus (accession number DQ811784.2 NCBI website): TGGGGAGTAATGAACCC GGTAATGTCGGTGGTAATGATGCTCTGGCAACCTC CACTATCTTTACACAAAGCCGTGTTATTAGCTCTTTTACATGT and a sequence within the human bocavirus NS1 gene: TAATGACTGCAGACAACGCCTAGTTGTTTGGT GGGAGGAGTGCTTAATGCACCAGGATTGGGTGG AACCTGCAAAGTGTATCTTGGGCGGGACAG. These were inserted into a pEX-A plasmid vector (Eurofins MWG Operon, Ebersberg Germany) and propagated in Escherichia coli. For use in the coronavirus RT-PCR, the plasmid was linearized using BamHI restriction enzyme (New England BioLabs, Ipswich USA) and RNA transcribed using the T7 High Yield RNA synthesis Kit (New England BioLabs, Ipswich USA). Purified RNA or DNA was quantified using UV spectrophotometry and used to construct the standard curves used for quantitation in each of the PCR assays. To optimize the primer concentration, duplicate preparations of coronavirus 229E (obtained from Public Health England Type Culture Collection, Salisbury, UK), pEX-A RNA template, 20, 10, 7.50, $5 \mu \mathrm{M}$ serial dilutions of forward and reverse primer and 10, 6.60, 3.3, $0.37 \mu \mathrm{M}$ probe concentrations were set up in MicroAmp Fast Reaction PCR tubes and mounted on a 48 well plate. Similarly, for analytical sensitivity of the $\mathrm{hBoV}$ PCR, 1:4 serial dilutions (in duplicates) of the pEX-A plasmid (Eurofins MWG Operon, Ebersberg Germany) were used in standard curve experiments.

PCR for identification of coronaviruses and bocavirus in samples

The Power SYBR Green RNA-to-CT 1-Step Kit (Applied Biosystems) was used in a one-step RT-PCR for detection of coronavirus, the reaction mixture comprised: $10 \mu$ of Power SYBR Green RT-PCR Master Mix (2×), $2.5 \mu \mathrm{l}$ forward and reverse primer $(20 \mu \mathrm{M}), 1 \mu \mathrm{l}$ of Arrayscript RT Enzyme mix (125X), $2 \mu \mathrm{l}$ of RNAse free water and $3 \mu \mathrm{l}$ of RNA template in positive control well or sample in test wells. For identification of bocavirus the Power SYBR Green PCR Master Mix (Applied Biosystems) was used: reaction mixture $10 \mu \mathrm{l}$ of Power SYBR Green PCR Master Mix $(2 \times), 2.5 \mu$ l forward and reverse primer $(20 \mu \mathrm{M}), 2 \mu \mathrm{l}$ RNAse free water and $3 \mu \mathrm{l}$ of template in positive control well or sample in test wells. RT-PCR experiments were conducted on the StepOne and StepOne Plus Real Time PCR machine (Applied Biosystems) with cycling parameters for coronavirus of: $48{ }^{\circ} \mathrm{C}$ for $30 \mathrm{~min}, 95^{\circ} \mathrm{C}$ for $10 \mathrm{~min}$; followed by 40 cycles of denaturing at $95{ }^{\circ} \mathrm{C}$ for $15 \mathrm{~s}$ and $57^{\circ} \mathrm{C}$ for $1 \mathrm{~min}$; and a melting curve of $95{ }^{\circ} \mathrm{C}$ for $15 \mathrm{~s}, 57^{\circ} \mathrm{C}$ for $15 \mathrm{~s}$ and $95{ }^{\circ} \mathrm{C}$ for $15 \mathrm{~s}$. The bocavirus PCR used $95^{\circ} \mathrm{C}$ for $10 \mathrm{~min}, 40$ cycles of $95^{\circ} \mathrm{C}$ for $15 \mathrm{~s}$ and $60^{\circ} \mathrm{C}$ for $1 \mathrm{~min}$ and a melting curve of $95{ }^{\circ} \mathrm{C}$ for $15 \mathrm{~s}, 60{ }^{\circ} \mathrm{C}$ for $15 \mathrm{~s}$ and $95^{\circ} \mathrm{C}$ for $15 \mathrm{~s}$. The number of viral copies was calculated using the absolute quantification method published by Brankatschk et al. [23].

\section{Confirmation of positive samples using MGB probes}

Samples that were positive for coronavirus or bocavirus were confirmed with a TaqMan based RT-PCR. The probe concentrations were first optimized using duplicate preparations of $10,6.6,5,3.3,0.3 \mu \mathrm{M}$ and 0.12 probe concentrations. Each well contained $10 \mu \mathrm{l}$ of TaqMan Fast Universal PCR Master Mix (2X) (Applied Biosystems), $2.5 \mu$ of probe, $2.5 \mu \mathrm{l}$ forward and reverse primer, $2 \mu \mathrm{l}$ of RNAse free water and $3 \mu l$ of RNA template. The coronavirus PCR also contained the $1 \mu \mathrm{l}$ Multiscribe Reverse Transcriptase (Applied Biosystems) and $1 \mu \mathrm{l}$ of RNase inhibitor. The cycling conditions were; for coronavirus experiments: $50{ }^{\circ} \mathrm{C}$ for $2 \mathrm{~min}, 95^{\circ} \mathrm{C}$ for $20 \mathrm{~s}$, followed by 40 cycles of $95{ }^{\circ} \mathrm{C}$ for $1 \mathrm{~s}$ and $57{ }^{\circ} \mathrm{C}$ for $20 \mathrm{~s}$; whereas for bocavirus: $95^{\circ} \mathrm{C}$ for $20 \mathrm{~s}$, followed by 40 cycles of $95^{\circ} \mathrm{C}$ for $1 \mathrm{~s}$ and $60{ }^{\circ} \mathrm{C}$ for $20 \mathrm{~s}$.

Polyacrylamide gel (PAGE) electrophoresis

Amplicons for coronavirus and bocavirus PCR were visualized using precast $8 \%$ TBE polyacrylamide gel $1 \mathrm{~mm} 15$ well (Applied Biosystems) run on an XCell SureLock ${ }^{\mathrm{TM}}$ Mini-Cell Electrophoresis chamber (Invitrogen Novex Mini cell), filled with 200 and $600 \mathrm{ml} 1 \times$ BTE Running Buffer in upper and lower chambers respectively. Ten $(10 \mu \mathrm{l})$ of PCR product was mixed with $9 \mu$ of Deionised water and $1 \mu \mathrm{l} 5 \times$ DNA Loading Buffer (Bioline, London) and loaded into the wells and the positive control well loaded with HyperLadder V (Bioline). The loaded XCell SureLock $^{\mathrm{TM}}$ Mini-Cell chamber was run at $200 \mathrm{~V}, 18 \mathrm{~mA}$ for 35 min, stained with GelRed Nucleic Acid Stain (Biotium, Hayward, UK) for $30 \mathrm{~min}$, and visualised under UV light on an Alphaimager 2200 machine (Alpha Innotech, San Leandro, Calif). 


\begin{tabular}{|c|c|c|c|c|c|c|}
\hline & $\begin{array}{l}\ldots \mid \ldots \\
21845\end{array}$ & $\begin{array}{l}\ldots \mid \ldots \\
21855\end{array}$ & ${ }_{21865}$ & 21875 & 21885 & 21895 \\
\hline \multirow[t]{3}{*}{ Consensus } & WYHYVHRGWH & BWHSWNNBKK & HRVYWKHBKN & VKNYNHYRNH & MBAGATTGGT & CTCGGGYGTT \\
\hline & ----- & ---1 & ---------- & --- & $--\overline{-}$ & --1 \\
\hline & ${ }_{21905}$ & $\begin{array}{l}\ldots|\ldots| \\
21915\end{array}$ & ${ }_{21925} \ldots$ & ${ }_{21935} \ldots$ & ${ }_{21945}$ & $\ldots$ \\
\hline \multirow{3}{*}{$\begin{array}{l}\text { Consensus } \\
\text { F Primer }\end{array}$} & CCATTAGACC & ССТСАТТАСТ & TGGGCCATTA & CAGCCACCAT & TACTACGAGA & CCGTTGGAKK \\
\hline & $-------\mathrm{ACC}$ & ССТСАТTACT & TGGGCCATTA & CA-------- & ---------- & ---------- \\
\hline & $\cdots{ }_{21965}$ & ${ }_{21975}$ & $\cdots$ & ${ }_{21995}$ & $\cdots \cdots|\cdots|$ & $\cdots{ }_{22015}$ \\
\hline & BSDDAGWDRT & SYDWHNYBDH & RNDDHWWNHD & WRNRRAWBYD & SANVNDBNYD & WWMNNWBHYD \\
\hline \multirow{2}{*}{ R Primer } & ---------- & $--------\overline{-}$ & ------------ & ------------ & $\overline{---}--------$ & ---------- \\
\hline & ${ }_{22025}$ & ${ }_{22035}$ & ${ }_{22045}$ & $\cdots{ }_{22055}$ & $\cdots 22065$ & ${ }_{22075}$ \\
\hline \multirow[t]{2}{*}{ Consensus } & NYRDMMDWHN & NVDWYNHVDB & DHKKNRVRWD & DVVBNNTBNV & TRBYRNVVNT & YYBDNYNHSV \\
\hline & & & & & & - \\
\hline
\end{tabular}

Fig. 1 A section of the consensus sequence (showing the region identical in all coronaviruses, derived from consensus sequences for 15 coronaviruses) that was used to design pan-coronavirus primers. The sequence of region conserved in all coronaviruses is underlined,

\section{Statistical analysis}

Two by two tables were drawn to describe the patterns of co-infection between influenza A virus, human coronavirus and human bocavirus and differences in distribution of single and dual infections by age, sex, and season. Differences were assessed using the Pearson's Chi square $\left(\chi^{2}\right)$ statistic, and for small samples, the Fisher's exact test. Association between single and mixed virus infection and admission to a general ward (GW) or intensive care unit (ICU) were assessed using simple logistic regression models. All statistical analyses were performed with STATA software, version 11.0. (STATACorp, Texas 77845, USA).

\section{Ethics}

Ethical approval for the study was obtained from the National Health Service-Research Ethics Committee (NHS-REC), reference number 11/NW/0698), the University of Manchester Research Ethics Office. Research and Development R\&D approval was obtained from the Central Manchester Universities Hospitals NHS Foundation Trust (reference number R01835) (Fig. 1)

\section{Results}

Efficiency, analytical sensitivity and reproducibility of the $\mathrm{hCoV}$ and $\mathrm{hBoV}$ PCRs

The optimum concentration for primers was $2.5 \mu \mathrm{l}$ $(20 \mu \mathrm{M})$ whereas the optimum concentration of the probe the positions here are in positive sense orientation, because of variations in the sizes of coronavirus genomes, in bovine coronavirus, the amplicon region lies between nucleotide 20062 and 20156

was $2.5 \mu \mathrm{l}(6.6 \mu \mathrm{M})$. The optimum annealing temperature for the primers was $57{ }^{\circ} \mathrm{C}$. At this temperature, the wells that contained coronavirus 229E and RNA template; gave the lowest threshold cycle (Ct value), (range 19-38), highest fluorescence signal (range 0.6-19.2), and the PCR product melted at $76.2{ }^{\circ} \mathrm{C}$, which is within the $\mathrm{Tm}$ for coronaviruses PCR products $\left(75.0\right.$ and $\left.80.0{ }^{\circ} \mathrm{C}\right)$. Analytical sensitivity of the PCR assays was tested by seven 1:4 serial dilutions $\left(10^{4}-10^{0}\right)$ for the $\mathrm{hCoV}$ and eleven serial dilution $\left(10^{6}-10^{0}\right)$ for the $\mathrm{hBoV}$. The $\mathrm{hCoV}$ assay was able to detect down to 2.6 copies/ $\mu \mathrm{l}$, whereas the $\mathrm{hBoV}$ was able to detect down to 4.9 copies/ $\mu$ l. Under optimum conditions, the duplicate samples gave reproducible results and the experiments were repeated three times giving a total number of 21 and 33 replicates. Our results compare well with previously published protocols of hCoV and hBoV. For example a SYBR Green RT-PCR assay for identification of $\mathrm{hCoV}$, published in 2007, Escutenaair et al. [24] reported that their assay was able to detect down to 10 RNA copies/ $\mu$, whereas Vijgen et al. [25] pan-coronavirus assay (published in 2008) was far less sensitive with a lower detection limit of $5.0 \times 10^{3}$ RNAcopies per microliter sample, Adach et al. [26] (1 and 10 genome copies). Further, hBoV assay by Neske et al. [27] was able to detect up to $3.8 \times 10^{8}-3.8 \times 10^{3}$ copies $/ \mu \mathrm{l}$ and $\mathrm{Lu}$ et al. [28] (10 copies). Our assays were therefore of good analytical sensitivity and could be used in diagnosis of hCoV. Polyacrylamide gel results indicated that the size of the PCR products obtained from the coronavirus $229 \mathrm{E}$ and bocavirus was similar to the coronavirus and bocavirus inserts into the $\mathrm{pEX}-\mathrm{A}$ plasmid vector (a picture of the PAGE result for coronavirus is provided in Fig. 2). 


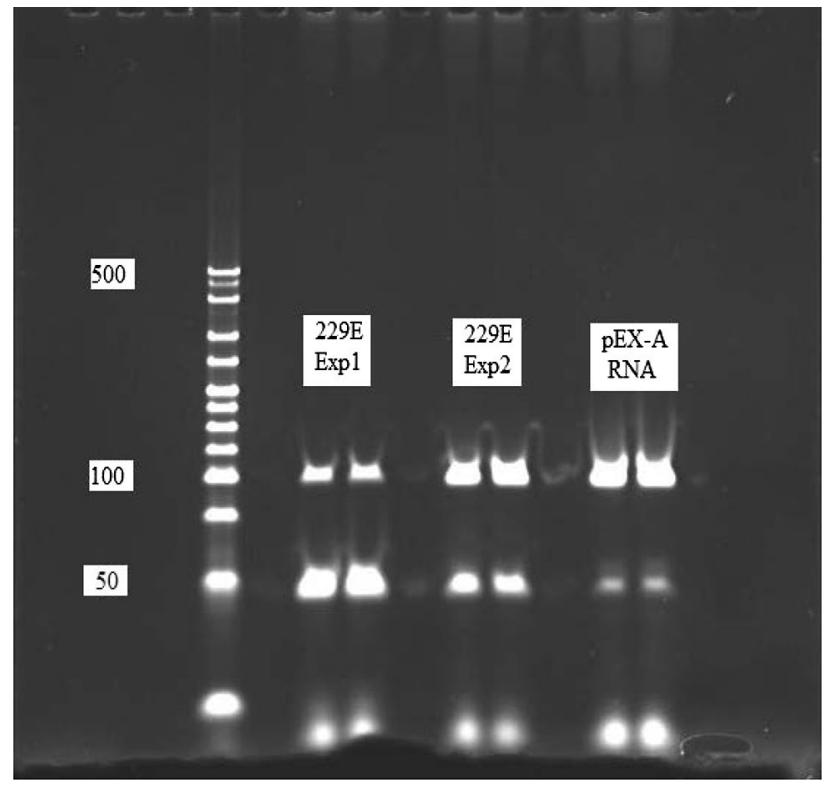

Fig. 2 Polyacrylamide gel electrophoresis of hCoV PCR products. PCR products from two experiments, one where each well contained $3 \mu \mathrm{l}$ of hCoV229E RNA (Exp1) and another $5 \mu \mathrm{l}$, to increase yield (Exp2) and products from RNA produced from the pEX-A vector. HypperLadder V marks are from bottom, 25, 50, 75, 100 bp up to 500. The marks at $50 \mathrm{bp}$ are due to primer dimmers which are known to form in SYBR Green PCRs

Respiratory virus infections in samples that were positive for influenza A viruses

Of the 217 influenza A virus samples included in this study, the majority $95.4 \%$ (207) were seasonal influenza A viruses and only $10(4.6 \%)$ were pandemic influenza A(H1N1)pdm09 infections. This was because the pandemic virus did not circulate in high numbers during the 2011/2012 season. The World Health Organisation (WHO) had declared the end of the pandemic on 10th August 2010 [29]. Human coronaviruses were found in 12 of the 217 samples whereas human bocavirus in 17 of the 217 samples. The $\mathrm{C} t$ values for $\mathrm{hCoV}$ positive samples ranged from 21.95 to 35.0 (mean 31.3) corresponding to 122 and 75 copies/ $\mu$ respectively, whereas for hBoV it ranged from 26.95 to 36.0 with (mean of 32.75 ) corresponding to 123 and 92 copies/ $\mu \mathrm{l}$, indicating low viral loads. Previous studies have also reported finding $\mathrm{hBoV}$ low and not high viral loads Zhenqiang et al. [12].

The same samples used for identification of hCoV and $\mathrm{hBoV}$ were also previously tested for other respiratory virus infections: influenza B virus (Flu B), respiratory syncytial virus (RSV), rhinoviruses (RV), adenovirus (AdV), human metapneumovirus (hMPV), and human parainfluenza virus types 1-3 (hPIV1-3). When the results of other respiratory viruses are included, $149(72.0 \%)$ of the 207 seasonal influenza A viruses were single infections, and more than one virus was detected in $58(28.0 \%)$ cases. Only 1 of the 10 patients with pandemic influenza $\mathrm{A}(\mathrm{H} 1 \mathrm{~N} 1) \mathrm{pdm} 09$ virus infection was also infected with human coronavirus and rhinovirus. Of the 34 co-infections between seasonal influenza $\mathrm{A}$ and other respiratory viruses; 19 cases were infected with hMPV, 14 with RV, 2 with Flu B, 2 with RSV, and 2 with hPIV3 virus.

Demographic and other characteristics of single and dual infections

The age, sex, and season distribution of patients are given in (Table 2). The majority of seasonal influenza A single infections and $\mathrm{hCoV}$ and $\mathrm{hBoV}$ co-infections were in adults $>19$ years old. Specifically, 104/149 (69.8\%) of single seasonal influenza A virus infections were in adults $>19$ years compared to $8 / 11(72.7 \%)$ of SeasFluA/hCoV co-infections and 9/13 (69.2\%) of SeasFluA/hBoV co-infections in adults $>19$ years old (and these differences were not statistically significant)-Table 2. However co-infections between Flu A and other respiratory viruses were significantly higher among children $<5$ years old $(11.2 \%-14 / 34$; $p=0.03$ ). Regarding seasonal distribution, most of both single and dual virus infections occurred during the winter season (with summer season having low virus activity). This is probably because we tested for $\mathrm{hCoV}$ and $\mathrm{hBoV}$ in samples that were positive for influenza $\mathrm{A}$ viruses and influenza viruses are known to circulate in high numbers mainly in winter seasons.

A larger percentage $(61.5 \% ; 8 / 13)$ of SeasFluA/hBoV co-infections were identified in patients that were admitted to either a general ward $(\mathrm{GW})$ or the intensive care unit (ICU) compared to $44.3 \%(66 / 149)$ of single SeasFlu A virus infections (OR $2.595 \%$ CI 0.67-9.34, $p=0.17)$. In a stratified analysis, there was a trend towards higher association between Flu $\mathrm{A}, \mathrm{hCoV}$ and $\mathrm{hBoV}$ with increasing age, but none of these were statistically significant (Table 2). In children $\leq 5$ years, $50 \%(1 / 2)$ of SeasFluA/hCoV and $66.7 \%(2 / 3)$ of SeasFluA/hBoV coinfections were admitted to a $\mathrm{GW}$ or ICU compared to $26.5 \%(9 / 34)$ of single influenza A virus infections. Comparatively, among patients aged 24-45 years old, $66.7 \%$ (2/3) with SeasFluA/hCoV co-infection were admitted either to a GW/ICU compared to $56.3 \%$ (18/32) of those with single seasonal influenza A virus infections (OR 2.20, $95 \%$ CI $0.46-10.35, p=0.32)$, and $100 \%(3 / 3)$ of SeasFluA/hBoV co-infections were admitted to a GW/ICU. Similarly among those aged $>65$ years old, $75.0 \%(3 / 4)$ of those with SeasFluA/hBoV co-infection were admitted to GW/ICU compared to $60.0 \%(27 / 45)$ with single seasonal influenza A virus infections (OR 6.0, $95 \%$ CI 0.46-76.54, $p=0.17)$ and $100 \%(1 / 1)$ of SeasFluA/hCoV co-infection 
Table 2 Demographics and disease severity in single, dual and multiple seasonal influenza A virus infections

\begin{tabular}{|c|c|c|c|c|}
\hline Variable & SeasFlu A only & SeasFlu A + hCoV & SeasFlu A + hBoV & SeasFlu A + other RVIs \\
\hline \multicolumn{5}{|l|}{ Age (years) $-n(\%)$} \\
\hline$\leq 5$ & $34(22.8)$ & $2(18.2)$ & $3(23.1)$ & $14(41.2)^{*}$ \\
\hline $5-19$ & $11(7.4)$ & $1(9.1)$ & $1(7.7)$ & $2(5.9)$ \\
\hline $19-24$ & $6(4.0)$ & $0(0.0)$ & $0(0.0)$ & $2(5.9)$ \\
\hline $24-45$ & $32(21.5)$ & $3(27.3)$ & $3(23.1)$ & $7(20.6)$ \\
\hline $45-65$ & $21(14.1)$ & $4(36,4$ & $2(15.4)$ & $4(11.8)$ \\
\hline$>65$ & $45(30.2)$ & $1(9.1)$ & $4(30.8)$ & $5(14.7)$ \\
\hline Total & $149(100)$ & $11(100)$ & $13(100)$ & $34(100)$ \\
\hline Male sex & $68(49.3)$ & $7(63.6)$ & $6(46.2)$ & $17(50.0)$ \\
\hline \multicolumn{5}{|l|}{ General ward/ICU-n $(\%)$} \\
\hline Age $<5$ & $9 / 34(26.5)$ & $1 / 2(50.0)$ & $2 / 3(66.7)$ & $3 / 14(21.43)$ \\
\hline$>5 \leq 19$ & $0 / 0(0.0)$ & $0 / 0(0.0)$ & $0 / 0(0.0)$ & $0 / 0(0.0)$ \\
\hline$>19 \leq 24$ & $1 / 6(16.7)$ & $0 / 0(0.0)$ & $0 / 0(0.0)$ & $0 / 2(0.0)$ \\
\hline$>24 \leq 45$ & $18 / 32(56.3)$ & $2 / 3(66.7)$ & $3 / 3(100)$ & $4 / 7(57.1)$ \\
\hline$>45 \leq 65$ & $11 / 21(52.4)$ & $0 / 4(0.0)$ & $0 / 2(0.0)$ & $2 / 4(50.0)$ \\
\hline$>65$ & $27 / 45(60.0)$ & $1 / 1(100)$ & $3 / 4(75.0)$ & $3 / 5(60.0)$ \\
\hline Total & $66 / 149(44.3)$ & 4/11 (36.6) & $8 / 13(61.5)$ & $12 / 34(35.3)$ \\
\hline OR $(95 \% \mathrm{CI} ; p \text { value })^{\mathrm{a}}$ & Baseline & $0.60(0.15-2.40 ; 0.47)$ & $2.5(0.67-9.34 ; 0.17)$ & $0.87(0.37-2.10 ; 0.76)$ \\
\hline
\end{tabular}

Seasflu A seasonal influenza A virus, $h C o V$ human coronavirus, $h B o V$ human bocavirus, other $R V I s$ co-infection between seasonal influenza A and other respiratory viruses (viruses involved; $\mathrm{hBoV}=4$, rhinovirus $=14$, influenza $\mathrm{B}=2$, respiratory syncytial virus $=2$, adenovirus $=4$, human metapneumovirus $=19$ and parainfluenza virus type $3=1$ )

* The statistic was significant at $p \leq 0.05$

a Odds ratios were adjusted for age group and sex

was admitted to a GW/ICU (Table 2). The lack of statistical significance was probably because most of the cells in the $>5-19,>19-24$ and $>45-65$ years age groups had zero observations; when these age groups were eliminated from the analysis, SeasFluA/hBoV co-infections was associated with a significant increase in risk of admission to GW/ICU (OR: 5.83, 95\% CI: $1.03-32.93, p=0.05$ ).

Discussion and conclusion

The importance of developing a coronavirus RT-PCR assay that is able to identify both Alphacoronaviruses and Betacoronaviruses which attack animals and humans, and Gammacoronaviruses which attack birds, is that such assays could identify zoonotic coronaviruses associated with more severe disease in humans $[2,5,30,31]$. Therefore the clinical usability of any PCR assay for the identification of all or most coronaviruses depends on its ability to amplify a region which is common to all coronaviruses (both human and human adapted animal viruses), and its sensitivity. The primers for coronavirus we designed target the replicase ORF1b nsp15 (XendoU/NendoU) uridylate specific endonuclease gene, which is highly conserved among all coronaviruses [21, 22] and we confirmed our results with a TaqMan probe. The quality of primers depends, among others, on their ability not to give nonspecific amplifications. Our primers for identification of coronaviruses did not give nonspecific amplifications as indicated by the melting curves. In addition, the $\mathrm{hCoV}$ standard curve experiments indicated that the hCoV RT-PCR assay was able to pick up to 2 copies/ $\mu$ l of human coronavirus RNA template, our assays results compare equally with those of a previously published SYBR green assay for coronaviruses [24-26]. We are therefore confident that it could be applied for diagnosis of coronaviruses in clinical settings subject to further experiments in statistically significant number of samples.

Some studies have reported that co-infections are predominantly in younger and older patients [32-34]. In this study, single seasonal influenza A viruses were predominantly in adults $>18$ years old in agreement with our earlier published study [35]. Similarly a higher proportion of $\mathrm{hCoV}$ and $\mathrm{hBoV}$ co-infections were in adults 18 to 65 years old. This suggests high prevalence of hCoVs and $\mathrm{hBoV}$ among older patients. Comparatively the majority of other respiratory virus co-infections (RSV, RV, hMPV and hPIV1-3) were in children $\leq 5$ years old (Table 2 ). Regarding seasonality of the viruses, almost all the respiratory virus single and dual infections in this study were identified in the winter season. This could be because we tested 
for $\mathrm{hCoV}$ and $\mathrm{hBoV}$ in samples that were positive for influenza $\mathrm{A}$ viruses and influenza viruses are known to circulate mainly during winter season. Our findings are in agreement with other studies $[16,36]$, which also reported dual or multiple respiratory virus infections mainly occur during winter season.

This study did not find a significant association between seasonal influenza A viruses co-infection with $\mathrm{hCoV}$ and $\mathrm{hBoV}$ and severe disease. Given the high co-infection rates for bocavirus reported by other studies [3, 12], probably more bocavirus infections could have been identified if all the 3,804 samples received at the MMPL between June 2011 and June 2012 were tested. A possibility of finding more coronaviruses could also not be ruled out. A review by Schildgen et al. [3] suggested that human bocavirus may be a bystander and not a real pathogen; one of the evidence to this hypothesis being frequently identified co-infecting with other respiratory viruses, and also it is mostly identified in low copy numbers. However, the results of this study indicate a trend towards the hypothesis that $\mathrm{hBoV}$ coinfection might promote hospitalization especially among patients $>65$ years old and $>24 \leq 45$ years old. Further, a number of other factors; age, comorbidities, immune status, and bacterial co-infection, affect disease outcome [37-39]. However in this study we did not control for these factors as the datum did not have these variables. This may have affected our outcomes and this should be born in mind when interpreting our results.

In conclusion, our RT-PCR protocol for the identification of coronaviruses is sensitive, specific and reliable and could be used for diagnosis of coronaviruses. More and larger studies are needed to confirm the role of $\mathrm{hBoV}$ in causing severe disease when they co-infect with influenza A viruses.

Acknowledgments The authors would like to acknowledge the University of Manchester, the Manchester Academic Health Science Centre, and the Central Manchester University Hospitals NHS Foundation Trust and staff for their support in this research. This work was received financial and institutional support from the University of Manchester.

Conflict of interest All authors no conflict of interest.

\section{References}

1. Nair H, Brooks WA, Katz M, Roca A, Berkley JA, Madhi SA, et al. Global burden of respiratory infections due to seasonal influenza in young children: a systematic review and meta-analysis. Lancet. 2011;378:1917-30.

2. Masters PS. The molecular biology of coronaviruses. Adv Virus Res. 2006;66:193-292.

3. Schildgen O, Muller A, Allander T, Mackay IM, Volz S, Kupfer B, Simon A. Human bocavirus: passenger or pathogen in acute respiratory tract infections? Clin Microbiol Rev. 2008;21:291-304.
4. Lai MMC, Perlan S, Anderson LJ. Coronaviridae. In: Knipe DM, Griffin DE, Lamb RA, Straus SE, Howley PM, Martin MA, Roizman B, editors. Fields virology. Philadelphia: Lippincott Williams and Wilkins; 2007. p. 1305-35.

5. Weiss SR, Navas-Martin S. Coronavirus pathogenesis and the emerging pathogen severe acute respiratory syndrome coronavirus. Microbiol Mol Biol Rev. 2005;69:635-64.

6. World Health Orgnisation (WHO). Middle East respiratory syndrome coronavirus (MERS-CoV) summary and literature updateas of 11 June 2014. http://www.who.int/csr/disease/coronavirus_ infections/archive_updates/en/. Accessed 5 Nov 2014.

7. Public Health England (PHA). Acute respiratory illness associated with a new virus identified in the UK. London:PHA; 2012 (Press release) 2012.

8. Promed email. Novel coronavirus-Saudi Arabia: human isolate archive number. Archive number: 20120920.1302733. (2012) 20 Sept 2012.

9. Zaki AM, van BS, Bestebroer TM, Osterhaus AD, Fouchier RA. Isolation of a novel coronavirus from a man with pneumonia in Saudi Arabia. N Engl J Med. 2012;367:1814-20.

10. Bermingham A, Chand MA, Brown CS, Aarons E, Tong C, Langrish $\mathrm{C}$, et al. Severe respiratory illness caused by a novel coronavirus, in a patient transferred to the United Kingdom from the Middle East, September 2012. Euro Surveill. 2012;17:20290.

11. Allander T, Tammi MT, Eriksson M, Bjerkner A, Tiveljung-Lindell A, Andersson B. Cloning of a human parvovirus by molecular screening of respiratory tract samples. Proc Natl Acad Sci USA. 2005;102:12891-6.

12. Zhenqiang BA, Formenty PBH, Roth CE. Human bocavirus, a real respiratory tract pathogen. Afr J Microbiol Res. 2007;1:51-6.

13. Lusebrink J, Wittleben F, Schildgen V, Schildgen O. Human bocavirus-insights into a newly identified respiratory virus. Viruses. 2009;1:3-12.

14. Wright PF, Neuman G, Kawaoka Y. Orthomyxoviruses. In: Knipe DM, Griffin DE, Lamb RA, Straus SE, Howley PM, Martin MA, Roizman B, editors. Fields virology. Philadelphia: Lippincott Williams and Wilkins; 2007. p. 1690-789.

15. Richard N, Komurian-Pradel F, Javouhey E, Perret M, Rajoharison A, Bagnaud A, et al. The impact of dual viral infection in infants admitted to a pediatric intensive care unit associated with severe bronchiolitis. Pediatr Infect Dis J. 2008;27:213-7.

16. Drews AL, Atmar RL, Glezen WP, Baxter BD, Piedra PA, Greenberg SB. Dual respiratory virus infections. Clin Infect Dis. 1997;25:1421-9.

17. Qu XW, Duan ZJ, Qi ZY, Xie ZP, Gao HC, Liu WP, et al. Human bocavirus infection, People's Republic of China. Emerg Infect Dis. 2007;13:165-8.

18. Office of National Statistics (ONS). 2011 Census: Usual resident population by five-year age group, local authorities in the United Kingdom; Office for National Statistics, UK, 2012. http://www.ons. gov.uk/ons/rel/census/2011-census/population-and-householdestimates-for-the-united-kingdom/stb-2011-census-population-estimates-for-the-united-kingdom.html. Accessed 28 Dec 2012.

19. Ellis J, Iturriza M, Allen R, Bermingham A, Brown K, Gray J, Brown D. Evaluation of four real-time PCR assays for detection of influenza A(H1N1)v viruses. Euro Surveill 2009;14.

20. Hall TA. BioEdit: a user-friendly biological sequence alignment editor and analysis program for Windows 95/98/NT. Nucleic Acids Symp Ser. 1999;41:95-8.

21. Marra MA, Jones SJ, Astell CR, Holt RA, Brooks-Wilson A, Butterfield YS, et al. The Genome sequence of the SARS-associated coronavirus. Science. 2003;300:1399-404.

22. Ivanov KA, Hertzig T, Rozanov M, Bayer S, Thiel V, Gorbalenya AE, Ziebuhr J. Major genetic marker of nidoviruses encodes a replicative endoribonuclease. Proc Natl Acad Sci USA. 2004;101:12694-9. 
23. Brankatschk R, Bodenhausen N, Zeyer J, Burgmann H. Simple absolute quantification method correcting for quantitative PCR efficiency variations for microbial community samples. Appl Environ Microbiol. 2012;78:4481-9.

24. Escutenaire S, Mohamed N, Isaksson M, Thoren P, Klingeborn B, Belak S, et al. SYBR Green real-time reverse transcriptionpolymerase chain reaction assay for the generic detection of coronaviruses. Arch Virol. 2007;152:41-58.

25. Vijgen L, Moes E, Keyaerts E, Li S, Van RM. A pancoronavirus RT-PCR assay for detection of all known coronaviruses. Methods Mol Biol. 2008;454:3-12. doi:10.1007/978-1-59745-1819_1.:3-12.

26. Adachi D, Johnson G, Draker R, Ayers M, Mazzulli T, Talbot PJ, Tellier R. Comprehensive detection and identification of human coronaviruses, including the SARS-associated coronavirus, with a single RT-PCR assay. J Virol Methods. 2004;122:29-36.

27. Neske F, Blessing K, Tollmann F, Schubert J, Rethwilm A, Kreth HW, Weissbrich B. Real-time PCR for diagnosis of human bocavirus infections and phylogenetic analysis. J Clin Microbiol. 2007;45:2116-22.

28. Lu X, Chittaganpitch M, Olsen SJ, Mackay IM, Sloots TP, Fry AM, Erdman DD. Real-time PCR assays for detection of bocavirus in human specimens. J Clin Microbiol. 2006;44:3231-5.

29. World Health Organisation (WHO): H1N1 in post-pandemic period; 2010. http://www.who.int/mediacentre/news/statements/2010/h1n1_vpc_20100810/en/. Accessed 9 Nov 2011.

30. Peiris JS, Lai ST, Poon LL, Guan Y, Yam LY, Lim W, et al. Coronavirus as a possible cause of severe acute respiratory syndrome. Lancet. 2003;361:1319-25.

31. Guan Y, Peiris JS, Zheng B, Poon LL, Chan KH, Zeng FY, et al. Molecular epidemiology of the novel coronavirus that causes severe acute respiratory syndrome. Lancet. 2004;363:99-104.
32. Echenique IA, Chan PA, Chapin KC, Andrea SB, Fava JL, Mermel LA. Clinical characteristics and outcomes in hospitalized patients with respiratory viral co-infection during the $2009 \mathrm{H} 1 \mathrm{~N} 1$ influenza pandemic. PLoS One. 2013;8:e60845.

33. Razanajatovo NH, Richard V, Hoffmann J, Reynes JM, Razafitrimo GM, Randremanana RV, Heraud JM. Viral etiology of influenza-like illnesses in Antananarivo, Madagascar, July 2008-June 2009. PLoS One. 2011;6:e17579.

34. Peci A, Winter AL, Gubbay JB, Skowronski DM, Balogun EI, De LC, et al. Community-acquired respiratory viruses and co-infection among patients of Ontario sentinel practices, April 2009 to February 2010. Influenza Other Respir Viruses. 2013;7:559-66.

35. Goka E, Vallely P, Mutton K, Klapper P. Influenza A, viruses dual and multiple infections with other respiratory viruses and risk of hospitalisation and mortality. Influenza Other Respir Viruses. 2013;7:1079-87.

36. Tanner H, Boxall E, Osman H. Respiratory viral infections during the 2009-2010 winter season in Central England, UK: incidence and patterns of multiple virus co-infections. Eur J Clin Microbiol Infect Dis. 2012;31:3001-6.

37. Van Kerkhove MD, Vandemaele KA, Shinde V, Jaramillo-Gutierrez G, Koukounari A, Donnelly CA, et al. Risk factors for severe outcomes following 2009 influenza A (H1N1) infection: a global pooled analysis. PLoS Med. 2011;8:e1001053.

38. Jackson S, Mathews KH, Pulanic D, Falconer R, Rudan I, Campbell $\mathrm{H}$, Nair $\mathrm{H}$. Risk factors for severe acute lower respiratory infections in children: a systematic review and meta-analysis. Croat Med J. 2013;54:110-21.

39. Alvarez AE, Marson FA, Bertuzzo CS, Arns CW, Ribeiro JD. Epidemiological and genetic characteristics associated with the severity of acute viral bronchiolitis by respiratory syncytial virus. J Pediatr (Rio J). 2013;89:531-43. 